\title{
Diabetes after infectious hepatitis: a follow-up study
}

\author{
J M OLI, C NWOKOLO
}

British Medical fournal, 1979, 1, 926-927

The duration of remission in cases 6,7 , and 8 is recorded as being over four years because by 1974 (four years after the episodes of diabetes) results of oral glucose tolerance tests were normal in all three patients, who were subsequently lost to follow-up. In cases 9,10 , and

Summary and conclusions

Eleven patients (nine men, one woman, and one girl) aged 11-62 years who developed diabetes mellitus after an attack of infectious hepatitis during the Eastern Nigerian epidemic of $1970-2$ were followed up for two to nine years. One patient aged 60 years remained diabetic after the original illness. In the remaining 10 patients the diabetes remitted after three to nine months (mean 6.7 months) but in four it recurred after a remission lasting one and a half to four years (mean 2.6 years).

Results of this follow-up study seem to confirm that the pancreas is sometimes permanently damaged during infectious hepatitis.

\section{Introduction}

Disease of the pancreas, both structural (pancreatitis) ${ }^{12}$ and functional (diabetes), ${ }^{3-6}$ during viral hepatitis has been recorded. In a few of the patients studied in these reports the diabetes was attributed to steroid treatment, but in others steroids were not used. An epidemic of infectious hepatitis in Nigeria during 1970-2 after the civil war gave us an opportunity to reassess the clinical impression that some hepatitis viruses may be diabetogenic. We record here the results of following up for two to nine years 11 patients under our care who developed diabetes mellitus during the epidemic.

\section{Patients and methods}

Out of 119 patients who developed polyuria and glycosuria during the epidemic of infectious hepatitis in Eastern Nigeria during 1970-2, 11 were followed up between 1970 and 1978 either at a diabetic clinic or by special invitation to this hospital. During the follow-up visits the patients were questioned about their symptoms, urine samples were examined for sugar, and fasting blood glucose concentrations were estimated. In four patients standard oral glucose tolerance tests were carried out to support the clinical impression that the diabetes had disappeared; and in some patients liver function tests were carried out, which entailed measuring serum bilirubin, aminotransferase, and alkaline phosphatase concentrations. We successfully followed up four patients for nine years, one for six years, three for five years, and three for two years.

\section{Results}

Table I shows the sex and age of the 11 patients, with the durations of their acute diabetes and remissions. We studied nine men, one woman, and one girl aged between 11 and 62 years. In all the patients except the man in case 1 the diabetes remitted after three to nine months (mean 6.7 months), but it recurred in four (cases 2-5) after a remission phase lasting one and a half to four years (mean 2.6 years).

\footnotetext{
Department of Medicine, University of Nigeria Teaching Hospital, Enugu, Nigeria

J M OLI, MB, MRCP, senior lecturer and consultant physician

C NWOKOLO, FRCPED, professor of medicine
} remitted.

TABLE I-Fasting blood glucose concentrations at presentation and durations of acute diabetes mellitus and remission in the 11 patients studied

\begin{tabular}{|c|c|c|c|c|}
\hline Case No & $\begin{array}{l}\text { Age and } \\
\text { sex }\end{array}$ & $\begin{array}{l}\text { Fasting blood } \\
\text { glucose } \\
\text { (mmol/1) }\end{array}$ & $\begin{array}{c}\text { Duration of } \\
\text { diabetes } \\
\text { (months) }\end{array}$ & $\begin{array}{c}\text { Duration of } \\
\text { remission } \\
\text { (years) }\end{array}$ \\
\hline $\begin{array}{r}1 \\
2 \\
3 \\
4 \\
5 \\
6 \\
7 \\
8 \\
9 \\
10 \\
11\end{array}$ & $\begin{array}{l}60, M \\
52, M \\
52, M \\
46, M \\
42, M \\
11, F \\
47, M \\
24, M \\
22, M \\
62, M \\
33, F\end{array}$ & $\begin{array}{r}19 \cdot 4 \\
\text { ND** } \\
\text { ND* } \\
11.4 \\
14.4 \\
8 \cdot 2 \\
10.6 \\
13.9 \\
13.1 \\
15.7 \\
12.9\end{array}$ & $\begin{array}{c}\text { Continuous } \\
9 \\
8 \\
6 \\
9 \\
4 \\
3 \\
6 \\
8 \\
5 \\
9\end{array}$ & $\begin{array}{c}\text { No remission } \\
2 \\
4 \\
1.5 \\
3 \\
>4 \\
>4 \\
>4 \\
\text { Not known } \\
\text { Not known } \\
\text { Not known }\end{array}$ \\
\hline
\end{tabular}

Table II shows when the 11 patients had diabetes or were in remission during 1970-8. The patient in case 1 developed diabetes in 1971 and remained diabetic until 1976, when he defaulted. After remission the patients in cases $2,3,4$, and 5 remained diabetic until the end of the study. Results of oral glucose tolerance tests in 1974 were normal in the patients in cases 6,7 , and 8 , who defaulted from follow-up thereafter.

All the patients were of normal weight during their periods of diabetes and remission apart from the man in case 2 . He was overweight in 1974 but, despite reducing his weight to normal by dieting, went on to require daily insulin until the end of the study. None of the 11 patients had a family history of diabetes. The diabetics who were successfully followed up, one until 1974, the other until 1978, had not developed any complications of diabetes, and results of liver function tests were normal.

\section{Discussion}

Our results indicate that out of 11 patients who developed diabetes mellitus during an epidemic of infectious hepatitis, five had become permanently diabetic by the fifth year after the original attack of hepatitis. Three others were in apparent remission (confirmed by oral glucose tolerance tests) up to four years after the original illness but were then lost to follow-up. The remaining three appeared to be in remission when seen one year after the original illness but were lost to follow-up thereafter.

Clearly, therefore, infectious hepatitis could be diabetogenic; but what is the mechanism ? Some workers ${ }^{3-6}$ who had recorded similar events after infectious hepatitis expressed various views about the pathogenesis of the diabetes mellitus. Francis and Osuntokun ${ }^{5}$ thought that their cases were hepatogenous. Their results contained no evidence of persisting hepatic damage after the hepatitis-in fact, all except one of their patients had apparently recovered completely from their hepatitis. The term hepatogenous diabetes is usually applied to diabetics with chronic liver disease such as cirrhosis, with the latter usually preceding the diabetes and clinical manifestations of diabetes other than glycosuria being absent. ${ }^{7}{ }^{8}$ Liver biopsy performed in 1977 on the patient in case 4 was normal, and the results of liver function 
TABLE II-Details of whether patients had diabetes (D) or were in remission $(R)$ during 1970-8, with mean $( \pm S D)$ fasting blood glucose concentrations (in mmolll) and results of oral glucose tolerance tests

\begin{tabular}{|c|c|c|c|c|c|c|c|c|c|}
\hline $\begin{array}{l}\text { Case } \\
\text { No }\end{array}$ & 1970 & 1971 & 1972 & 1973 & 1974 & 1975 & 1976 & 1977 & 1978 \\
\hline $\begin{array}{r}1 \\
2 \\
3 \\
4 \\
5 \\
6 \\
7 \\
8 \\
9 \\
10 \\
11\end{array}$ & $\begin{array}{l}\mathrm{D} \\
\mathrm{D} \\
\mathrm{D} \\
\mathrm{D} \\
\mathrm{D} \\
\mathrm{D} \\
\mathrm{D}\end{array}$ & $\begin{array}{c}\mathrm{D} \\
\mathrm{R} ; 3.9 \\
\mathrm{R} ; 3 \cdot 8 \\
\mathrm{R} ; 4.4 \pm 0 \cdot 3 \\
\mathrm{R} ; 4 \cdot 3 \\
\mathrm{R} ; 3.8 \\
\mathrm{R} ; 4 \cdot 1 \\
\mathrm{R} ; 3.9 \\
\mathrm{D} \\
\mathrm{R} ; 4.4\end{array}$ & $\begin{array}{c}\mathrm{D} \\
\mathrm{R} ; 4 \cdot 2 \pm 0 \cdot 4 \\
\mathrm{R} ; 4 \cdot 0 \pm 0 \cdot 5 \\
\mathrm{D} ; 1 \pm \cdot 1 \cdot 4 \\
\mathrm{R} ; 4 \cdot 1 \pm 0 \cdot 4 \\
\mathrm{R} ; 3 \cdot 3 \\
\mathrm{R} ; 3 \cdot 7 \pm 0 \cdot 2 \\
\mathrm{R} ; 4 \cdot 3 \\
\mathrm{R} ; \mathbf{4} \cdot \mathbf{4} \\
\mathrm{D}\end{array}$ & $\begin{array}{c}D \\
D ; 13.9 \\
R ; 4.3 \pm 0.2 \\
D=0.3 \\
R ; 3.8 \pm 0.3 \\
R ; 3.7 \pm 0.3 \\
R ; 3.8 \\
R ; 4.1 \pm 0.3 \\
R ; 3.9 \pm 0.6\end{array}$ & $\begin{array}{c}\text { D } \\
\text { D } \\
\text { OGT normal } \\
\text { D } \\
\text { D; } 11 \cdot 0 \\
\text { OGTT normal } \\
\text { OGTT normal } \\
\text { OGTT normal }\end{array}$ & $\begin{array}{l}\mathrm{D} \\
\mathrm{D} \\
\mathrm{D} \\
\mathrm{D} \\
\mathrm{D}\end{array}$ & $\begin{array}{l}\mathrm{D} \\
\mathrm{D} \\
\mathrm{D} \\
\mathrm{D} \\
\mathrm{D}\end{array}$ & $\begin{array}{l}\mathrm{D} \\
\mathrm{D} \\
\mathrm{D} \\
\mathrm{D}\end{array}$ & $\begin{array}{l}\text { D } \\
\text { D } \\
\text { D } \\
\text { D }\end{array}$ \\
\hline
\end{tabular}

OGTT = Oral glucose tolerance test.
Conversion: SI to traditional umits-Blood glucose: $1 \mathrm{mmol} / 1 \approx 18 \mathrm{mg} / 100 \mathrm{ml}$.

tests in the four patients who remained diabetic were also normal. These patients are unlikely to have hepatogenous diabetes.

The other possibility is that this is a coincidence, and that all these patients would have had diabetes whether or not they had developed infectious hepatitis. This seems unlikely because in the diabetic clinic held by one of us (JO) 15 out of 169 new diabetics $(8.8 \%)$ dated their diabetes from an episode of "yellow eyes." Francis and Osuntokun ${ }^{5}$ reported on seven out of 832 diabetics over 10 years whose diabetes was "caused by acute parenchymal liver disease." This is higher than the $0.3 \%$ and $0.26 \%$ prevalences of diabetes in the hospital populations at Ibadan and Enugu respectively. ${ }^{910}$

Did these people have latent diabetes that was unmasked by infectious hepatitis or steroids used to treat the hepatitis? Several factors in our cases militate against this possibility. All our patients developed their diabetes in the convalescent stages of the hepatitis, after the peak of the illness had passed. None gave a history of diabetic episodes or a family history of diabetes. Only one patient (case 1) was given steroids, but in small doses of $20 \mathrm{mg}$ of prednisolone daily for a week during the early stages of the infectious hepatitis. No other known diabetogenic drugsfor example, thiazide diuretics-were given to any of our patients. All our patients were of normal weight during their periods of diabetes and remissions apart from the man in case 2; but with dieting to normal weight his diabetes did not disappear. We think that the virus of infectious hepatitis damaged the pancreatic islets in these diabetics. Those patients with slight damage developed latent diabetes, which became overt as the patients got older. Those with a severely damaged pancreas-for example, the patient in case 1 -became overtly diabetic, like the 15 out of 169 patients in our diabetic clinic here and the seven cases reported by Francis and Osuntokun. ${ }^{5}$

Was the hepatitis due to hepatitis $A$ ? The epidemic nature of hepatitis in an environment after a civil war favours an infection such as hepatitis $A$, though the absence of a similar record of diabetes in the Indian and other epidemics is difficult to explain. ${ }^{112}$ Serological tests carried out by Francis et al ${ }^{13}$ during the epidemic showed that it was not due to hepatitis $B$. They found only a few patients with a low titre of complementfixation antibodies to yellow fever, but most patients had no clinical or serological evidence of this disease. No other arboviruses-for example, chikungunya or zika-were isolated from the sera; and the patients seen in our hospital did not show clinical or laboratory features of leptospirosis.

Our experience in these cases, as well as in cases in some diabetic clinics in Nigeria, suggests that damage to the pancreas by the virus of infectious hepatitis should be considered among the possible causes of diabetes mellitus, at least in some tropical areas.

We are grateful to Miss C Ogbogu for her secretarial help.

\section{References}

${ }^{1}$ Achord, J L, fournal of the American Medical Association, 1968, 205, 837. Gillespie, W J, fournal of the Royal College of Surgeons of Edinburgh, 1973, $18,120$.

${ }^{3}$ Moskovich, E G, and Tregubova, K L, Problemy Endokrinologii i Gormonoterapii, 1966, 12, 40.

${ }^{4}$ Franczak, T, Polski Tygodnik Lekarski, 1969, 24, 1705.

5 Francis, T I, and Osuntokun, B O, fournal of the Nigeria Medical Association, 1970, 7, 47.

- Adi, F C, British Medical fournal, 1974, 1, 183.

${ }^{7}$ Sherlock, S, Diseases of the Liver and Biliary System, 5th edn, p 510. Oxford, Blackwell Scientific, 1975.

${ }^{8}$ Megyesi, C, Samols, E, and Marks, V, Lancet, 1967, 2, 1051.

- Osuntokun, B O, et al, West African Medical fournal, 1971, 295, 312.

${ }^{10} \mathrm{Oli}, \mathrm{J} \mathrm{M}$, personal communication, 1978.

${ }^{11}$ Chuttani, H K, et al, British Medical fournal, 1966, 2, 676.

${ }_{12}$ Cullinan, E R, King, R C, and Rivers, J S, British Medical fournal, 1958, $1,1315$.

${ }^{13}$ Francis, T I, Smith, J A, and Wright, S G, Tropical and Geographical Medicine, 1972, 24, 44.

(Accepted 5 February 1979)
ONE HUNDRED YEARS AGO The introduction of physical exercise and instruction on hygiene as a part of a college curriculum has been realised at Amherst College, United States, for the last twenty years, and with results that are highly instructive. Only distinguished members of the medical profession are appointed to the department, and they have the same footing as the other professors. Their first duty is to know the physical condition of each student, and to see that the laws of health are preserved. In case of sickness the student applies to this officer for a certificate, whereby he is excused from college duties and put under suitable treatment. Statistics of the bodily condition of the students are regularly secured. All the classes are required to attend the gymnasium exercises four times a week. The performances are accompanied with music, and arranged to give full play to the animal spirits. They are fully as popular and well attended as the literary exercises. The intelligent co-operation of the students is secured by instruction on the means of preserving health, physical and mental, with supplementary lectures on human anatomy and physiology. Writing on the chances of life of the young men under this hygienic discipline, as compared with men of the same age elsewhere, Professor Hitchcock says: "It is regarded as an established law that the chances of life grow less and less from about the fifteenth to the twenty-third year, and the rate of decrease is very rapid. But the tables of health kept at Amherst show that there is an improvement in health from year to year through the course, the ages being from nineteen to twenty-three; for, taking the number of sick men in the freshmen class as unity, the number in the sophomore class is 9.012 , in the junior 0.759 , and in the senior but 0.578 ; the percentage during the college course diminishing to nearly one-half." In the light of these twenty years' experience, he urges on colleges generally the formation of a similar department. (British Medical fournal, 1879.) 